\title{
Quality of Life of Patients Treated With Implant-Supported Mandibular Overdentures Evaluated With the Oral Health Impact Profile (OHIP-14): a Survey of 58 Patients
}

\author{
Ritva Kuoppala ${ }^{1}$, Ritva Näpänkangas ${ }^{1}$, Aune Raustia ${ }^{1}$ \\ ${ }^{1}$ Department of Prosthetic Dentistry and Stomatognathic Physiology, Institute of Dentistry, Oral and Maxillofacial Department, \\ Oulu University Hospital, Oulu, Finland.
}

\author{
Corresponding Author: \\ Ritva Kuoppala \\ P. O. Box 5281, FI-90014 University of Oulu \\ Finland \\ Phone: +358407137072 \\ Fax: +35885375560 \\ E-mail: ritva.kuoppala@,oulu.fi
}

\begin{abstract}
Objectives: The purpose of this study was to evaluate the oral health-related quality of life of patients treated with implantsupported mandibular overdentures and to compare the attachment systems used.

Material and Methods: Altogether 112 patients treated with implant-supported mandibular overdentures in 1985 - 2004 were invited to the follow-up; 58 of them attended and replied to the Oral Health Impact Profile (OHIP-14) -questionnaire. There were 48 overdentures with a bar connection and 10 with a ball connection, the total number of implants installed and still in use was 197. The mean follow-up time was 13.7 years. The associations between the OHIP-14 variables and the patient's age, gender as well as the number of implants supporting the overdenture and the type of attachment used were assessed.

Results: The results showed that patients with implant-supported mandibular overdentures were satisfied with their oral health-related quality of life (OHRQoL). Older patients were more satisfied than younger ones in both genders. Neither the implant connection type nor the number of supporting implants seemed to have a significant influence on the OHRQoL.

Conclusions: Especially older patients with mandibular implant-supported overdentures were satisfied with their oral healthrelated quality of life. Attachment type or the number of supporting implants did not have a significant influence on the oral health-related quality of life.
\end{abstract}

Keywords: denture, implant-supported; dental implant; oral health; quality of life; outcome studies; mandible.

Accepted for publication: 19 June 2013

To cite this article:

Kuoppala R, Näpänkangas R, Raustia A. Quality of Life of Patients Treated With Implant-Supported Mandibular Overdentures Evaluated With the Oral Health Impact Profile (OHIP-14): a Survey of 58 Patients.

URL: http://www.ejomr.org/JOMR/archives/2013/2/e4/v4n2e4ht.pdf

doi: $10.5037 /$ jomr.2013.4204 


\section{INTRODUCTION}

Dental implants have been used in edentulous jaws to improve the retention and stability of complete dentures. Attachment to the implants improves the stability and function of the prostheses and increases patient satisfaction [1-4]. The implant connection also improves neuromuscular activity and adaptation and thereby substantially improves masticatory function in edentulous patients [5-12]. Implant treatment nearly doubles maximum bite forces compared with those achieved with conventional complete dentures, and jaw muscles are used in a more efficient way $[\underline{1}, \underline{13}]$.

Quality of life is affected in some way by oral health in the majority of people [14-16]. The type and quality of prosthetic constructions, and nowadays more often implant-supported prostheses, can be considered one aspect of oral health in elderly patients. The oral health impact profile index (OHIP-14) [17] has been used as a shortened 14-item questionnaire to evaluate the impact of oral health on the quality of life. The index measures people's perception of the social impact of oral disorders on their well-being. The OHIP-14 captures only negative impacts, whereas some other oral healthdependent quality of life instruments capture both positive and negative impacts. However, the OHIP is the most frequently used and best-documented instrument nowadays [18].

The aim of our retrospective study was to gather information about the outcome of treatment with implant-supported mandibular overdentures from the patients' perceptions by using the oral health impact profile index (OHIP-14) and to compare the attachment systems used. The research hypothesis was that implant connection in complete dentures results in a favourable assessment of patients' oral health-related quality of life.

\section{MATERIAL AND METHODS}

Altogether 112 patients treated with implant-supported mandibular overdentures between 1985 and 2004 were invited to the follow-up [2]. Patients were referred to specialist care to the Department of Oral and Maxillofacial Surgery in Oulu University Hospital being very demanding cases. Main indications for implant treatment of these patients were severe retention problems of conventional prostheses, recurrent mucosal pain and sore spots and problems with chewing related to advanced alveolar bone resorption.

The number of patients who took no contact and did not attend was 22 . Fourteen patients had no possibility to come or said they didn't want to come and 18 patients had died. In all, $58(51.8 \%)$ of the invited patients (46 female and 12 male) attended the examination; $33 / 58$ of the patients were treated during $1985-1994$ and 25/58 during 1995 - 2004. Fifty participants out of 58 gave answers to all the OHIP-14 items [18]. There were 6 persons with 1 missing answer and 2 persons with more than 2 missing answers.

The mean age of the patients examined was 55.2 years (range 37 to 78 ) at the time of the implantation procedure and 69 years (range 56 to 90 ) at the time of the follow-up, the mean follow-up time was 13.7 years (range 3.3 to 21.9).

The total number of implants installed and still in use was 197 (average number 3 implants/ overdenture, range 2 to 4 ), mean length $12 \mathrm{~mm}$ (range 8 to $21 \mathrm{~mm}$ ). There were altogether 48 overdentures with a bar connection and 10 with a ball connection. Fifty-three patients had a conventional complete denture in the opposite jaw, 2 patients had an implant-retained overdenture, 1 patient had an implant-supported fixed partial denture, 1 patient had a removable partial denture and 1 patient had his own teeth. The questionnaire (OHIP-14) was filled in by the patients before the clinical examination [17].

Every 7 dimension includes two items, yielding altogether 14 (OHIP 1-14). The seven dimensions are functional limitation, physical pain, psychological discomfort, physical disability, psychological disability, social disability and handicap. The five categories of response for each item are never $(=0)$, hardly ever $(=1)$, occasionally $(=2)$, fairly often $(=3)$ and very often $(=4)$. Higher OHIP scores indicate worse, and lower OHIP scores indicate better oral health-related quality of life.

This study of 58 patients was approved by the Ethical Committee of the Northern Ostrobothnia Hospital District.

\section{Statistical analysis}

The average values for the OHIP-14 were calculated using non-missing score values and the results were analyzed using ANOVA and Student's T-test. SPSS software (SPSS, Version 16.0, SPSS, Chicago, IL, USA) was used to perform the statistical analyses of the data. A significant level of $\mathrm{P}<0.05$ was used.

\section{RESULTS}

The frequencies of the seven different OHIP dimensions are presented in Figure 1A - G. The distribution of the patient's responses was uniform in all seven OHIP-14 dimensions except in the dimension of 'physical pain', 


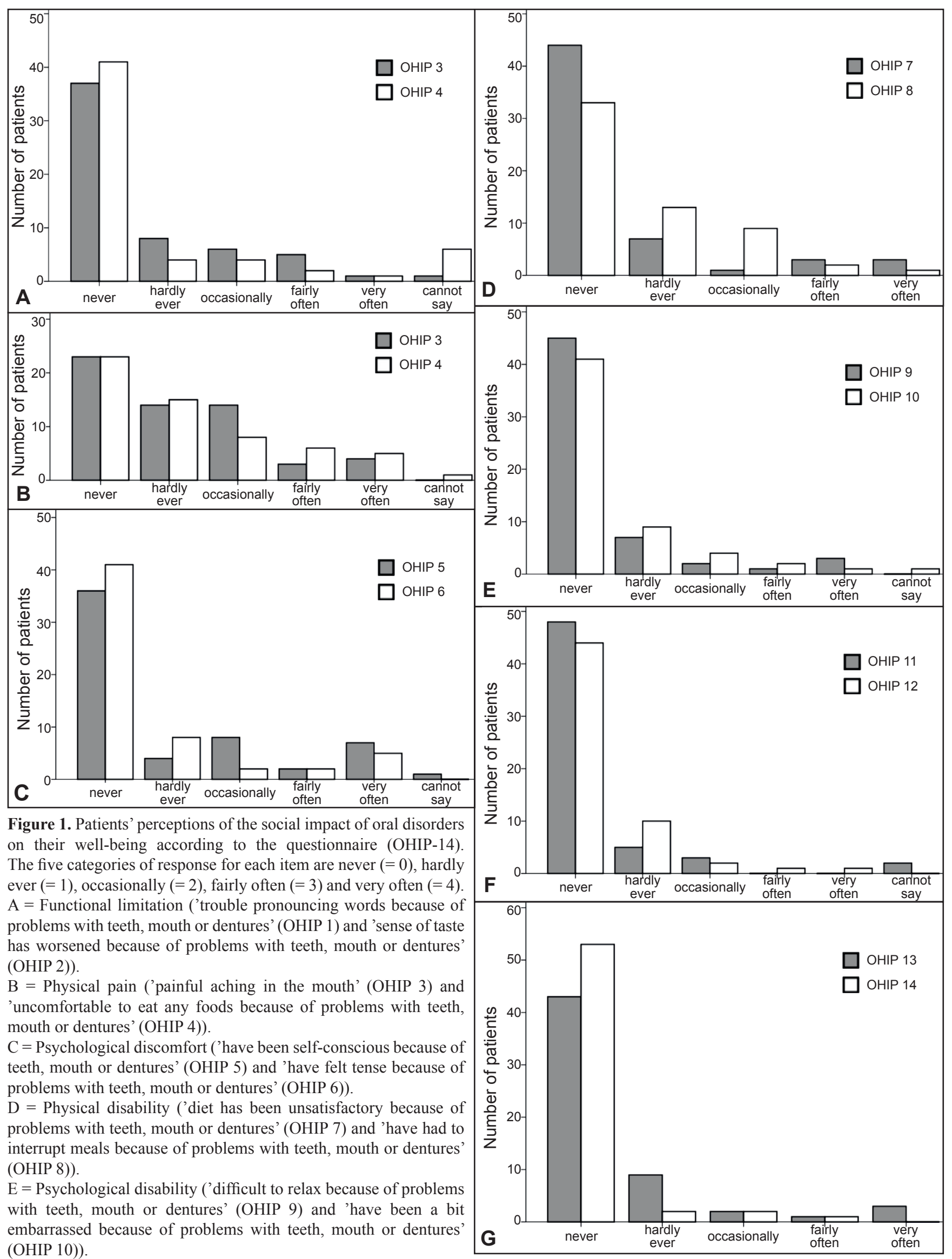
(OHIP 10)).

$\mathrm{F}=$ Social disability ('have been a bit irritable with other people because of problems with teeth, mouth or dentures' (OHIP 11) and 'have had difficulty doing usual jobs because of problems with teeth, mouth or dentures' (OHIP 12)).

$\mathrm{G}=$ Handicap ('have felt that life in general is less satisfying because of problems with teeth, mouth or dentures' (OHIP 13) and 'have been totally unable to function because of problems with teeth, mouth or dentures' (OHIP 14)). 
where fewer 'never' answers i.e. more complaints were reported by the patients (Figure 1B).

According to the questionnaire, it was seen that most of the patients were satisfied with their oral health and prostheses and there were no statistically significant differences between women and men $(\mathrm{P}>0.05)$. The youngest age group (patients under 65 years of age) seemed to differ from the older ones, who usually had fewer complaints in the dimensions of the OHIP-14 (Figure 2). The older patients reported 'never' answers more often than the patients under 65 years of age, whereas the patients under 65 years of age more often reported 'very often" or 'fairly often" answers in the OHIP-14 questionnaire. The subjects under 65 years of age seemed to be more dissatisfied with their

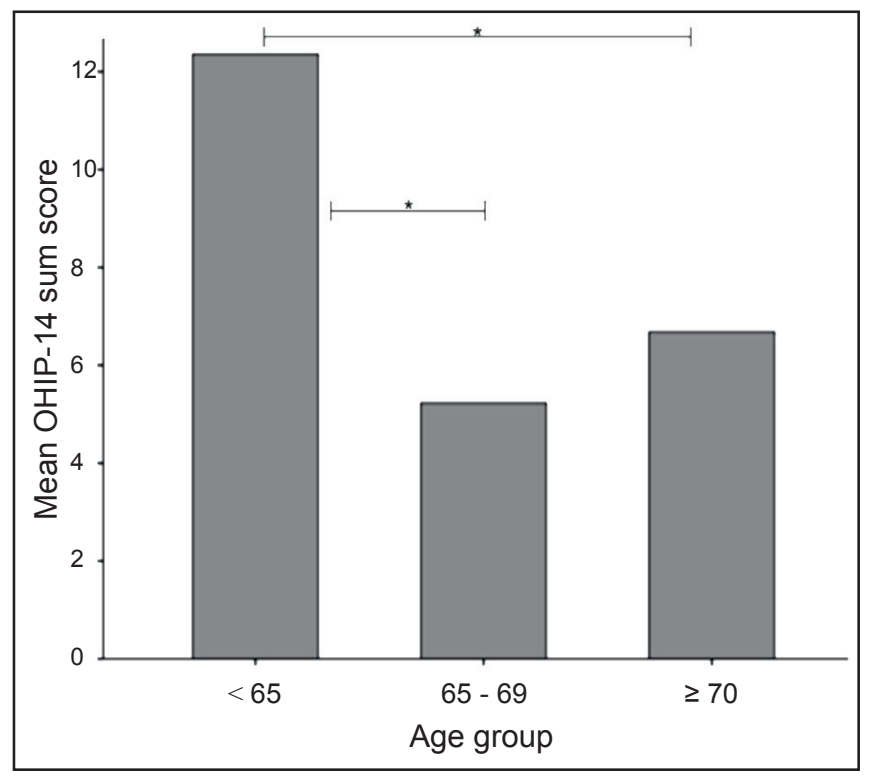

Figure 2. Mean OHIP-14 sum scores in three different age groups $(\mathrm{P}<0.05)$.

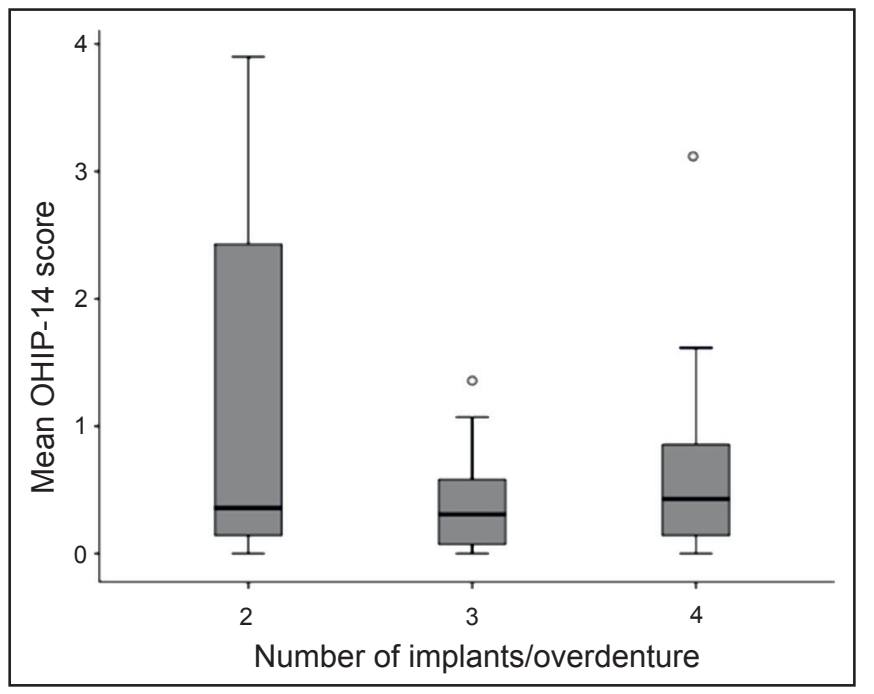

Figure 3. Mean OHIP-14 scores and number of implants per overdenture. No statistically significant difference was found between the groups $(\mathrm{P}>0.05)$. quality of life, especially in terms of psychological discomfort and disability. They had been self-conscious and had felt tense because of their dentures and more often had had difficulty relaxing and more often had been embarrassed because of problems with their teeth, mouth or dentures. For example, $87 \%$ of the subjects in the older age groups, reported never having difficulty relaxing.

The number of implants supporting the overdenture as well as the connection type (bar or ball connection) did not have a statistically significant influence on the OHIP-14 values (P > 0.05) (Figure 3). It can be seen, however, that patients with two implants and an overdenture reported higher OHIP-14 values, but not significantly, which means more dissatisfaction with OHRQoL compared with patients with four implants and an overdenture. Slightly higher OHIP-14 values, but not significantly, i.e. more dissatisfaction, were also noted with a ball connection than with bars (Figure 4). When comparing the patient groups according to the time elapsed since completion of the prosthetic treatment (follow-up time 3 to 12 years and 13 to 22 years), no statistical differences were found in the OHIP-14 values.

\section{DISCUSSION}

According to the results of the present study, it can be seen that patients treated with implant-supported mandibular overdentures were satisfied with the outcome of the treatment when evaluated using the OHIP-14 questionnaire. The clinical situation recorded to be good, the prostheses functioned well and only few breakages were recorded in the prosthetic constructions

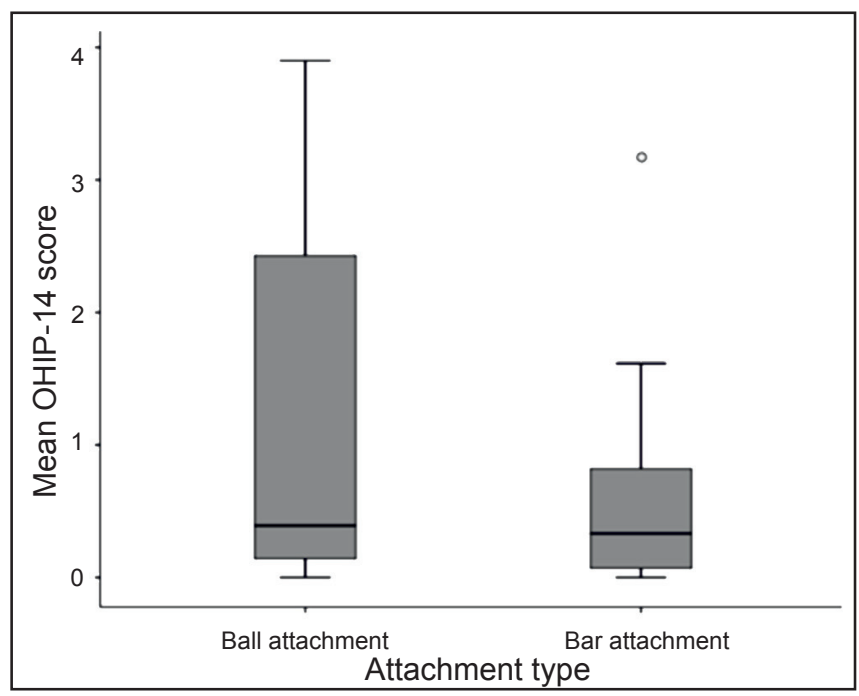

Figure 4. Mean OHIP-14 scores and attachment type in overdentures. No statistically significant difference was found between the groups $(\mathrm{P}>0.05)$. 
as reported earlier [2]. It must be noted that in some cases the follow-up time was over 20 years, and $67 \%$ of the patients examined still had their original overdenture in use [2]. In five cases long implants had been used in mandible, one patient having even $21 \mathrm{~mm}$ long implants, which was common in the 80 ' to achieve bicortical anchorage to implants.

No statistically significant difference was foundbetween the number of implants supporting an overdenture or the attachment system used when evaluated with the OHIP-14 [19]. Contrary to the study by Siadat et al. [16], gender did not correlate here with patient satisfaction.

Older patients were even more satisfied in the aspects of psychological discomfort and disability when compared with patients under 65 years of age. The people in the youngest age group were usually still involved in working life and had to cope with different social situations, and the demands of oral status might have been higher than in the older age groups.

It has been confirmed that older people often lack the facility to adapt to changes in edentulousness. The degree of adaptive capacity can be expected to influence the quality of life $[1,2]$. On the other hand, it has been noted that older people are even satisfied with less than ideal oral health and they have less unrealistic expectations of the treatment than younger patients. Less complaints about oral conditions among the elderly have been noted in several studies, for instance in the UK and the USA, with lower impact rankings in QoL reports, that is to say the impact of oral health problems on the quality of life decreases with increasing age $[14,16]$.

This study was retrospective and information given by the patients concerning their oral health-related quality of life with the aid of OHIP-14 questionnaire was not available before implant treatment. Every patient, however, had a history of severe problems related to use of conventional mandibular dentures. According to the present study, treatment outcome with implantsupported mandibular overdentures was found to be good and successful when evaluated with the oral health impact profile (OHIP-14).

\section{CONCLUSIONS}

The results of this retrospective study show that patients treated with implant-supported mandibular overdentures were satisfied with their oral health-related quality of life. Differences in age groups show that older patients were even more satisfied than younger ones. Gender as well as attachment type or the amount of connecting implants did not seem to be especially significant in this study.

\section{ACKNOWLEDGMENTS AND DISCLOSURE STATEMENTS}

The authors report no conflicts of interest related to this study.

\section{REFERENCES}

1. Heckmann SM, Heussinger S, Linke JJ, Graef F, Pröschel P. Improvement and long-term stability of neuromuscular adaptation in implant-supported overdentures. Clin Oral Implants Res. 2009 Nov;20(11):1200-5. [Medline: 19832766] [doi: 10.1111/j.1600-0501.2009.01722.x]

2. Kuoppala R, Näpänkangas R, Raustia A. Outcome of implant-supported overdenture treatment - a survey of 58 patients. Gerodontology. 2012 Jun;29(2):e577-84. Epub 2012 Jan 10. [Medline: 22616909] [doi: 10.1111/j.1741-2358.2011.00524.x]

3. Emami E, Heydecke G, Rompre P, de Grandmont P, Feine JS. Impact of implant support for mandibular dentures on satisfaction, oral and general health-related quality of life: a meta-analysis of randomized-controlled trials. Clin Oral Implants Res. 2009 Jun;20(6):533-44. [Medline: 19515032] [doi: 10.1111/j.1600-0501.2008.01693.x]

4. Thomason JM. The use of mandibular implant-retained overdentures improve patient satisfaction and quality of life. J Evid Based Dent Pract. 2010 Mar;10(1):61-3. [Medline: 20230974] [doi: 10.1016/j.jebdp.2009.11.022]

5. van der Bildt A, van Kampen FM, Cune MS. Masticatory function with mandibular implant-supported overdentures fitted with different attachment types. Eur J Oral Sci. 2006 Jun;114(3):191-6. [Medline: 16776767] [doi: 10.1111/j.1600-0722.2006.00356.x]

6. Turkyilmaz I, Company AM, McGlumphy EA. Should edentulous patients be constrained to removable dentures? The use of dental implants to improve the quality of life for edentulous patients. Gerodontology. 2010 Mar;27(1):3-10. Epub 2009 Mar 8. [Medline: 19291086] [doi: 10.1111/j.1741-2358.2009.00294.x]

7. Att W, Stappert C. Implant therapy to improve quality of life. Quintessence Int. 2003 Sep; 34(8):573-81. [Medline: 14620207]

8. Awad MA, Lund JP, Shapiro SH, Locker D, Klemetti E, Chehade A, Savard A, Feine JS. Oral health status and treatment satisfaction with mandibular implant overdentures and conventional dentures: a randomized clinical trial in a senior population. Int J Prosthodont. 2003 Jul-Aug;16(4):390-6. [Medline: 12956494] 
9. Allen PF, McMillan AS. A longitudinal study of quality of life outcomes in older adults requesting implant prostheses and complete removable dentures. Clin Oral Implants Res. 2003 Apr;14(2):173-9. [Medline: 12656876] [doi: 10.1034/j.1600-0501.2003.140206.x]

10. Carlsson GE, Omar R. The future of complete dentures in oral rehabilitation. A critical review. J Oral Rehabil. 2010 Feb;37(2):143-56. [Medline: 20002536] [doi: 10.1111/j.1365-2842.2009.02039.x]

11. Heydecke G, Locker D, Awad M, Lund JP, Feine JS. Oral and general health-related quality of life with conventional and implant dentures. Community Dent Oral Epidemiol. 2003 Jun;31(3):161-8. [Medline: 12752541] [doi: 10.1034/j.1600-0528.2003.00029.x]

12. Geckili O, Bilhan H, Mumcu E, Dayan C, Yabul A, Tuncer N. Comparison of patient satisfaction, quality of life, and bite force between elderly edentulous patients wearing mandibular two implant-supported overdentures and conventional complete dentures after 4 years. Spec Care Dentist. 2012 Jul-Aug;32(4):136-41. [Medline: 22784321] [doi: 10.1111/j.1754-4505.2012.00258.x]

13. van Kampen FM, vander Bildt A, Cune MS, Bosman F. The influence of various attachment types in mandibular implantretained overdentures on maximum bite force and EMG. J Dent Res. 2002 Mar;81(3):170-3. [Medline: 11881630] [doi: $10.1177 / 154405910208100305$ ]

14. Steele JG, Sanders AE, Slade GD, Allen PF, Lahti S, Nuttall N, Spencer AJ. How do age and tooth loss affect oral health impact and quality of life? A study comparing two national samples. Community Dent Oral Epidemiol. 2004 Apr;32(2):107-14. [Medline: 15061859] [doi: 10.1111/j.0301-5661.2004.00131.x]

15. McGrath C, Bedi R. Understanding the value of oral health to people in Britain - importance to life quality. Community Dent Health. 2002 Dec;19(4):211-4. [Medline: 12489834]

16. Siadat H, Alikhasi M, Mirfazaelian A, Geramipanah F, Zaery F. Patient satisfaction with implant-retained mandibular overdentures: a retrospective study. Clin Implant Dent Relat Res. 2008 May;10(2):93-8. [Medline: 18462205] [doi: 10.1111/j.1708-8208.2007.00065.x]

17. Slade GD. Derivation and validation of a short-form oral health impact profile. Community Dent Oral Epidemiol. 1997 Aug;25(4):284-90. [Medline: 9332805] [doi: 10.1111/j.1600-0528.1997.tb00941.x]

18. Strassburger C, Heydecke G, Kerschbaum T. Influence of prosthetic and implant therapy on satisfaction and quality of life: a systematic literature review. Part 1- Charasteristics of the studies. Int J Prosthodont. 2004 Jan-Feb;17(1):83-93. [Medline: 15008238]

19. MumcuE,BilhanH,GeckiliO.Theeffectofattachmenttypeandimplantnumberonsatisfactionandqualityoflifeofmandibular implant-retained overdenture wearers. Gerodontology. 2012 Jun;29(2):e618-23. Epub 2011 Jul 4. [Medline: 21726276] [doi: $10.1111 / \mathrm{j} .1741-2358.2011 .00531 . \mathrm{x}]$

\section{To cite this article:}

Kuoppala R, Näpänkangas R, Raustia A. Quality of Life of Patients Treated With Implant-Supported Mandibular Overdentures Evaluated With the Oral Health Impact Profile (OHIP-14): a Survey of 58 Patients.

J Oral Maxillofac Res 2013;4(2):e4

URL: http://www.ejomr.org/JOMR/archives/2013/2/e4/v4n2e4ht.pdf

doi: $10.5037 /$ jomr.2013.4204

Copyright (C) Kuoppala R, Näpänkangas R, Raustia A. Accepted for publication in the JOURNAL OF ORAL \& MAXILLOFACIAL RESEARCH (http://www.ejomr.org), 19 June 2013.

This is an open-access article, first published in the JOURNAL OF ORAL \& MAXILLOFACIAL RESEARCH, distributed under the terms of the Creative Commons Attribution-Noncommercial-No Derivative Works 3.0 Unported License, which permits unrestricted non-commercial use, distribution, and reproduction in any medium, provided the original work and is properly cited. The copyright, license information and link to the original publication on (http://www.ejomr.org) must be included. 